\title{
41. AGES OF SEDIMENTS RECOVERED FROM THE DEEP SEA DRILLING PROJECT PACIFIC LEGS 5 THROUGH 9, 16 THROUGH 21, AND 28 THROUGH 35
}

\author{
Hans M. Bolli, Department of Geology, Swiss Federal Institute of Technology, Zürich, and \\ University of Zürich, Switzerland
}

\begin{abstract}
The age of sediments recovered from 162 sites during the DSDP Pacific Ocean Legs 5 through 9, 16 through 21, and 28 through 35 are plotted in columnar sections in three tables, one for each phase of the drilling program. Stratigraphic gaps occurring in sedimentary sequences are shown to be the result of either intervals not cored $(\mathrm{C})$, hiatuses $(\mathrm{H})$, or both $(\mathrm{CH})$. The letter $\mathrm{B}$ at the bottom of a section indicates that basement/basalt has been reached. The degree of accuracy of the age determinations is also indicated. The purpose of this presentation is to provide quick reference of these data for all the sites drilled in the Pacific Ocean.
\end{abstract}

\section{INTRODUCTION}

With Site 325 of Leg 35, the Deep Sea Drilling Project completed the three phases of drilling by the Glomar Challenger in the Pacific Ocean carried out during, respectively, Legs 5 through 9,16 through 21 , and 28 through 35. Altogether 162 sites were drilled or attempted during this campaign: Sites 32 through 84 on Legs 5 through 9, Sites 155 through 210 on Legs 16 through 21, and Sites 270 through 279 and 283 through 325 on Legs 28 through 35 . Sites 280 through 282 of Leg 29 are situated west of longitude $150^{\circ}$ and are therefore considered as belonging to the Indian Ocean. Site 312 of Leg 32 was not drilled for technical reasons. Furthermore, no cores were retrieved at Site 201 of Leg 20. The geographic areas covered on the individual legs and the position of each site are shown in Figure 1.

\section{RESULTS AND DISCUSSION}

As done previously for the DSDP Sites of the Indian Ocean (Bolli and Saunders, 1977) and the Atlantic/Gulf of Mexico/Caribbean/Mediterranean and Black Sea (Bolli, 1979), this chapter summarizes sediment ages of the drilling sites in the Pacific (see Tables 1, 2, and 3) in such a manner that quick reference can be made to age intervals present and recovered. In addition to the sediment ages for each site, the degree of accuracy in age determinations is indicated by four different symbols. Apparent stratigraphic gaps in the column caused (at least in part) by discontinuous coring are shown by the letter $\mathrm{C}$, while established hiatuses are shown by an $\mathrm{H}$. $\mathrm{CH}$ indicates intervals where in addition to discontinuous coring, an actual hiatus is regarded as responsible for the stratigraphic gap. The letter B at the base of a section indicates that basement or basalt was reached.

Not shown in the tables are intervals with discontinuous coring within all or part of a period or stage, thicknesses of sedimentary sequences, lithology, core recovery, or fossils used for age determination. This supplemental, detailed information may be obtained directly from the core barrel sheets in the Initial Reports volumes.

Ages are taken from the core barrel sheets of the Site Reports. They are largely based on planktonic foraminiferal or calcareous nannoplankton data. Only occasionally are ages derived from other microfossils such as radiolarians, palynomorphs, diatoms, and fish denticles. In some cases, ages given on core barrel sheets differ slightly from those shown in the respective Site Reports or individual reports in the volumes.

When comparing ages of different legs, one has to be aware that these may be based on somewhat differing zonal schemes, both for planktonic foraminifers and for calcareous nannoplankton, and occasionally for radiolarians. However, such age differences are minimal and seldom cross period or stage limits. There is also no uniformity in the individual volumes in the subdivision of periods within the Tertiary and of stages in the Cretaceous and Jurassic. In the Tertiary, it is particularly the Pliocene, and in the Cretaceous, the Maestrichtian, and Albian which in some volumes are subdivided into "upper," "middle," and "lower," and in others only into "upper" and "lower." In some of the reports, the Pleistocene is not subdivided, while in others a lower and upper Pleistocene are distinguished. In exceptional cases, a middle Pleistocene may also be recognized.

The subdivision of Cretaceous stages into "upper," "middle," and "lower," or "upper" and "lower," is restricted in most volumes to the Upper Cretaceous and late Lower Cretaceous (Maestrichtian to Aptian), whereas the early Lower Cretaceous (Barremian to Berriasian) and the Upper Jurassic (Tithonian to Oxfordian) received no further subdivision. Exceptions to this occur occasionally such as in Site 166 of Leg 17, where upper Hauterivian is determined.

For the Indian Ocean and the Atlantic summaries, sites were arranged in a sequence based on geographic areas which brought out general trends in sediment ages 


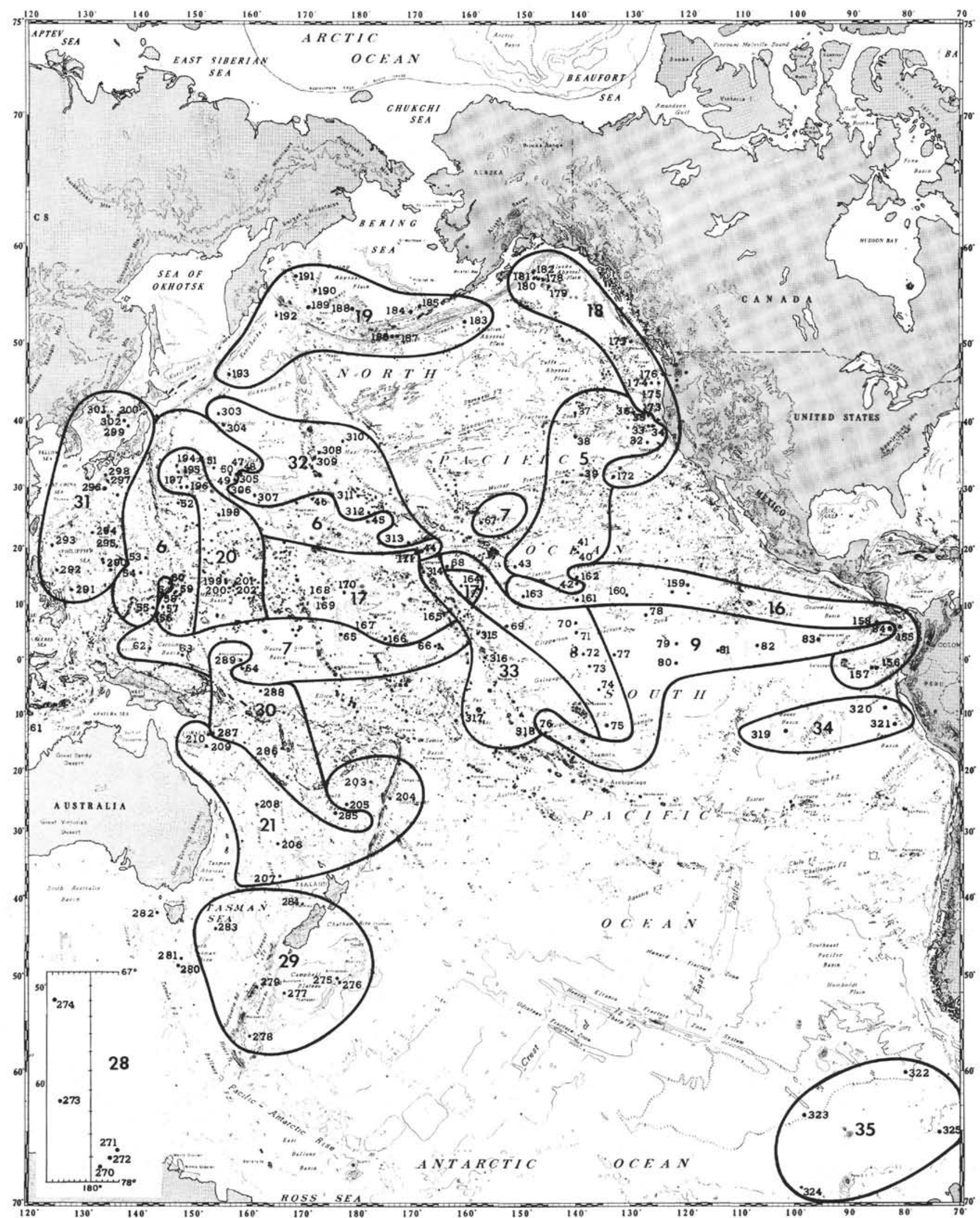

Figure 1. Map of the Pacific Ocean showing areas covered by Deep Sea Drilling Project Legs 5-9, 16-21, 28-35, and locations of sites drilled. 
and possible hiatuses in given areas. By such an arrangement, trends may however be strongly masked by those sites where the sedimentary sequence was not completely penetrated down to basement, or which were not continuously cored or had incomplete recovery.

In contrast to the Indian Ocean and Atlantic summaries, the Pacific legs and sites are here arranged strictly in chronological order: Legs 5 through 9 of Phase I (Table 1), Legs 16 through 21 of Phase II (Table 2), and Legs 28 through 35 of Phase III (Table 3). By such a chronological arrangement individual sites can easily be located in the three tables.

Figure 1, in addition to the site locations, shows the areas covered by each leg of Phases I through III. This provides an additional aid for locating sites of different legs that were operated in the same related areas.

\section{REFERENCES}

Bolli, H. M. and Saunders, J. B., 1977. Introduction to stratigraphy and paleontology. Indian Ocean Geology and Biostratigraphy. American Geophysical Union, p. 311-324.

Bolli, H. M., in press. The ages of sediments recovered from DSDP Legs 1-4, 10'15, and 36-53 (Atlantic, Gulf of Mexico, Caribbean, Mediterranean and Black Sea), In Donnelly, T., Francheteau, J., Bryan, W., Robinson, P., Flower, M., Salisbury, M., et al., Initial Reports of the Deep Sea Drilling Project, v. 51, 52, 53: Washington (U.S. Government Printing Office). 
TABLE 1

Pacific Ocean Legs 5 through 9: Ages of Sediments Recovered

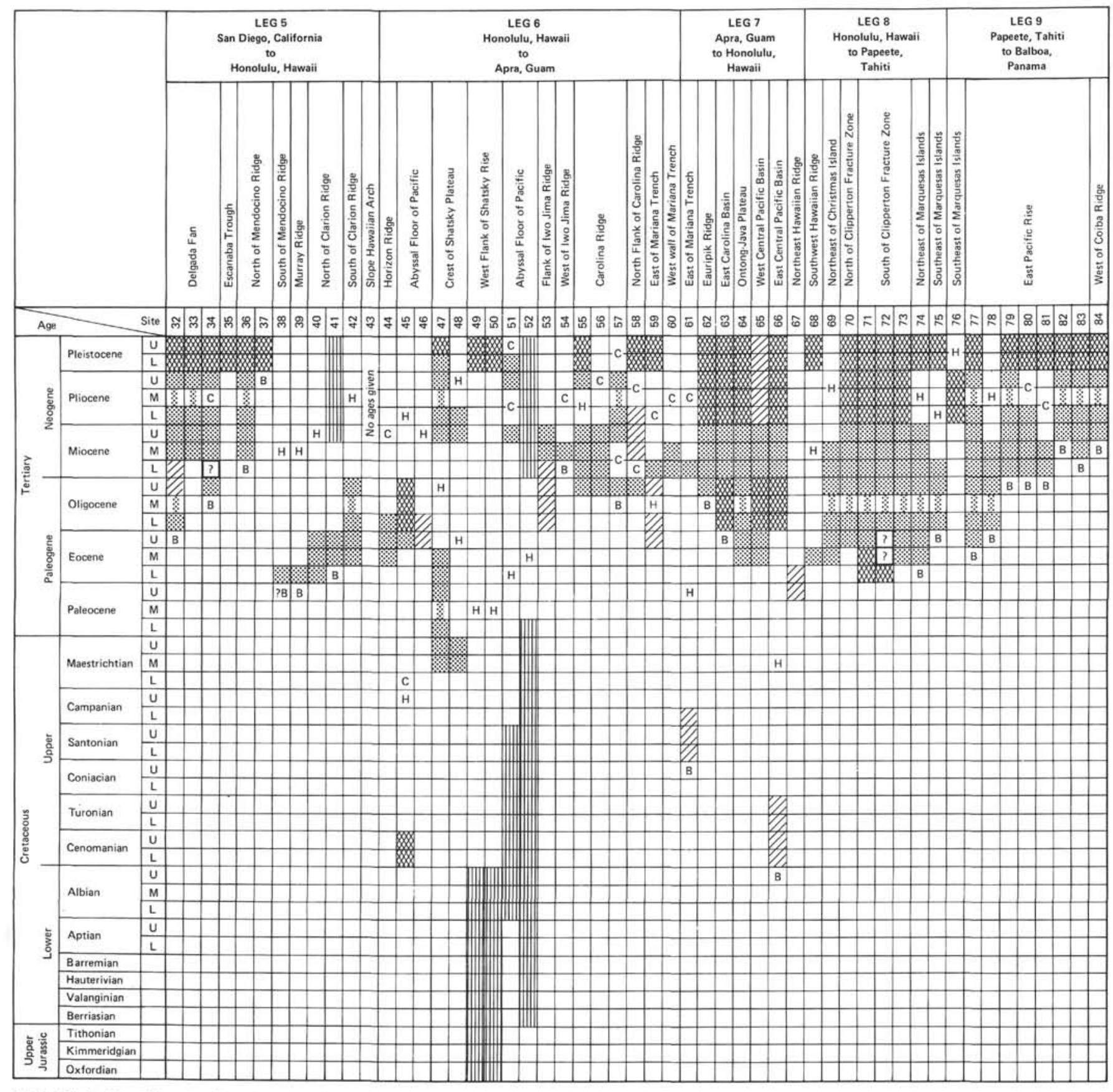

Subdivision of Epoch or Stage into upper (U), middle(M) and lower (L),

e.g. upper Miocene, lower Campanian

All or part of Period(s) or Stage(s) reported as only questionably present

Epoch or Stage without subdivision into upper, middle, lower, e.g. Oligocene, Albian

C Absence of Period or Stage caused at least in part by discontinuous coring

Age determination includes all or part of two adjacent Epochs or Stages, e.g. Oligocene to Eocene, lower Maestrichtian or Campanian

H Absence of all or part of Period or Stage caused by hiatus (within continuously cored intervals)

Age determination includes all or part of more than two Epochs or Stages, e.g. Lower Cretaceous, upper Santonian to middle Albian

$\mathrm{C}$ Interval missing because of both discontinuous coring and assumed hiatuses

$\$$ Middle part of an Epoch or Stage not recognized but apparently no hiatus present. Applies mostly to Pliocene, occasionally to other Periods or Stages

B Basement/basalt reached 
TABLE 2

Pacific Ocean Legs 16 through 21: Ages of Sediments Recovered

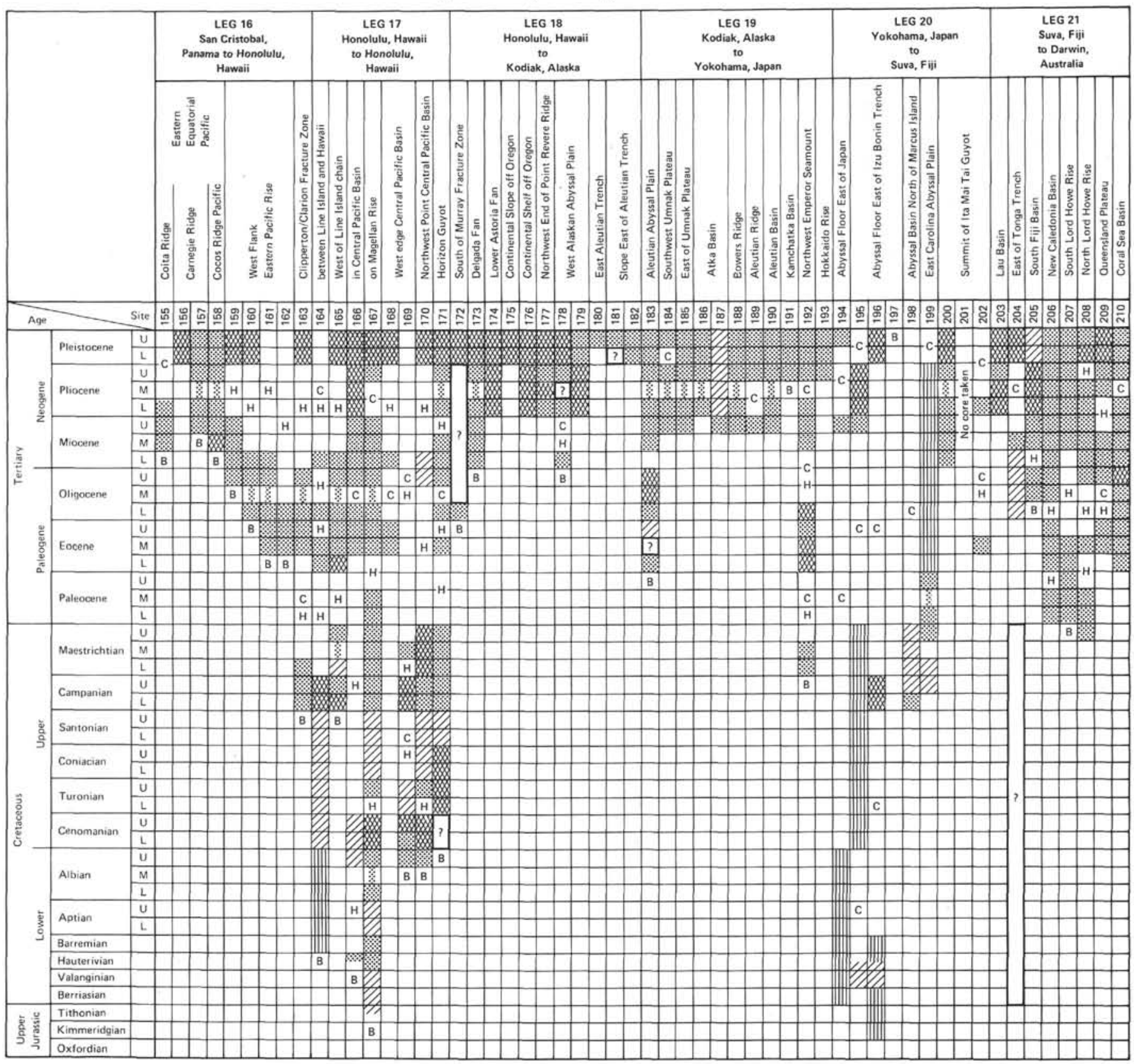


TABLE 3

Pacific Ocean Legs 28 through 35: Ages of Sediments Recovered

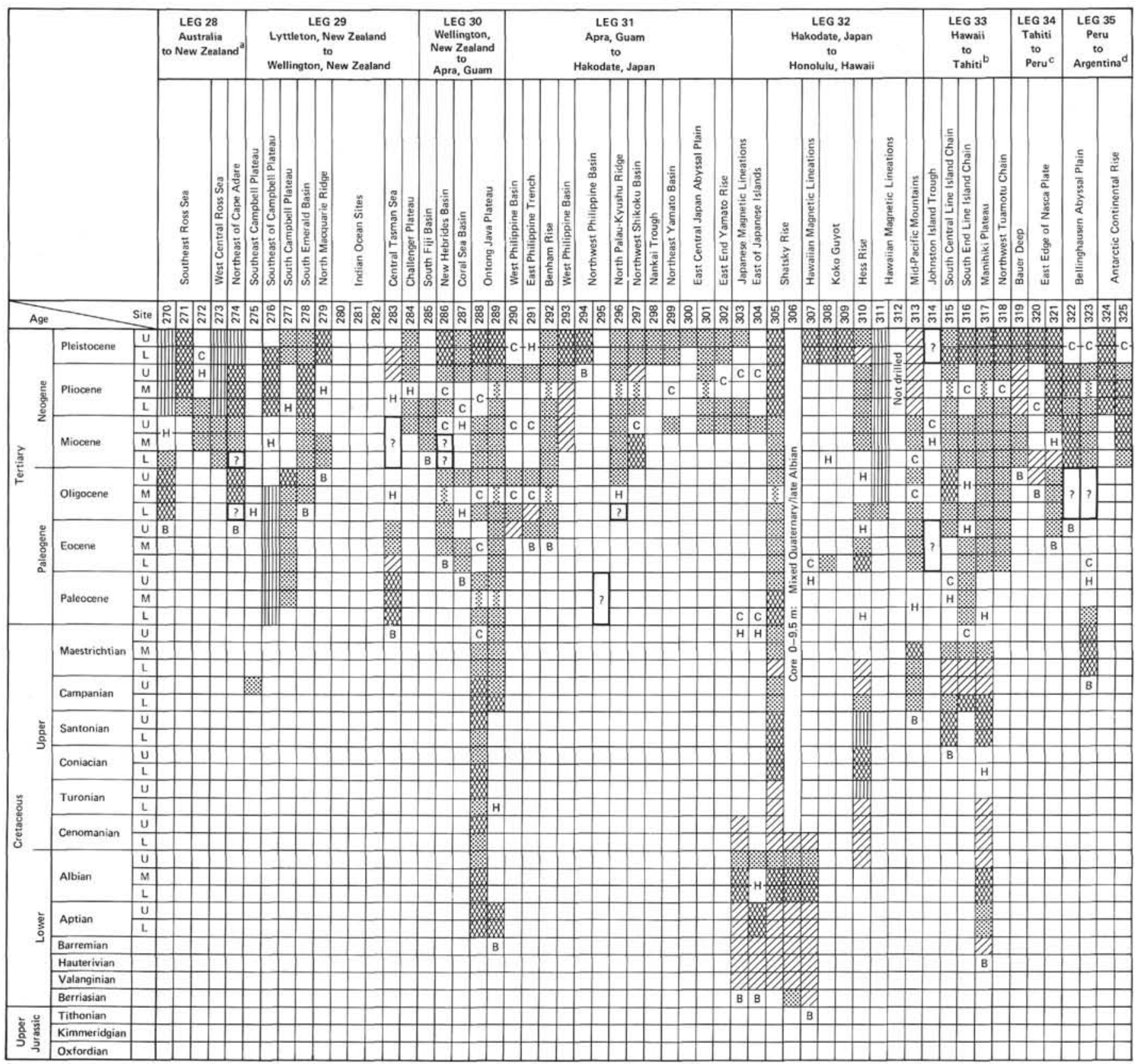

${ }^{2}$ Freemantle, Australia to Christchurch, New Zealand

${ }^{b}$ Honolulu, Hawaii to Papeete, Tahit

cPapeete, Tahiti to Callao, Peru

dCallao, Peru to Ushuaia, Argentina 